\title{
Astragaloside IV protects new born rats from anesthesia-induced apoptosis in the developing brain
}

\author{
JIAN SUN $^{1,2^{*}}$, XIAO-LING CHEN $^{3 *}$, JIN-YU ZHENG $^{4}$, JIAN-WEI ZHOU $^{1}$ and ZHENG-LIANG MA ${ }^{5}$ \\ ${ }^{1}$ Department of Molecular Cell Biology and Toxicology, School of Public Health, Nanjing Medical University, Nanjing, \\ Jiangsu 210029; ${ }^{2}$ Department of Anesthesiology, Maternal and Child Health Hospital of Huai'an; \\ ${ }^{3}$ Department of Nephrology, The Affiliated Huai'an Hospital of Xuzhou Medical College, Huai'an, Jiangsu 223002; \\ ${ }^{4}$ Department of Neurosurgery, The Affiliated Huai'an Hospital of Xuzhou Medical College, Huai'an, Jiangsu 223003; \\ ${ }^{5}$ Department of Anesthesiology, Drum Tower Clinical Medical School, Nanjing Medical University, \\ Nanjing, Jiangsu 210029, P.R. China
}

Received June 9, 2015; Accepted May 27, 2016

DOI: 10.3892/etm.2016.3519

\begin{abstract}
Exposure to general anesthesia may cause severe neurotoxicity in developing brain due to neuronal apoptosis. Astragaloside IV (AS IV) has antioxidant and antiapoptosis properties; however, its effects on anesthesia-induced neuroapoptosis have not been studied. In the present study, we determined whether AS IV pre-treatment is able to reduce isoflurane exposure-induced neuroapoptosis in rats. New born rats were pre-treated with AS IV or solvent by oral gavage for three days, then exposed to isoflurane. The results showed that pre-treatment of AS IV significantly inhibited isoflurane-induced neural apoptosis in the hippocampus of new born rats, and such protection was accompanied by reduced levels of caspase- 3 , nuclear factor- $\kappa \mathrm{B}$ activation and phosphorylated c-Jun $\mathrm{N}$-terminal kinase, extracellular signal-regulated kinase and increased levels of B-cell lymphoma-2, glycogen synthase kinase-3 $\beta$, Klotho and phosphorylated protein kinase B. Furthermore, AS IV pre-treatment significantly alleviated isoflurane-induced oxidative stress and proinflammatory cytokine release in the rat hippocampus and serum. In summery, the results of the study demonstrated that AS IV is able to protect
\end{abstract}

Correspondence to: Dr Jian-Wei Zhou, Department of Molecular Cell Biology and Toxicology, School of Public Health, Nanjing Medical University, Nanjing, Jiangsu 210029, P.R. China

E-mail: jianweizhou024@126.com

Dr Zheng-Liang Ma, Department of Anesthesiology, Drum Tower Clinical Medical School, Nanjing Medical University, Nanjing, Jiangsu 210029, P.R. China

E-mail: zhengliangma024@126.com

*Contributed equally

Key words: astragaloside IV, anesthesia, neurotoxicity, oxidative stress, inflammation developing brain from anesthesia-induced neuroapoptosis via anti-oxidant and anti-inflammatory activities.

\section{Introduction}

Anesthetics may damage the brain during the synaptogeneic phase of neurodevelopment due to their property at the $\mathrm{N}$-methul-D-aspartic acid and $\gamma$-aminoburyric acid A receptors (1-3). The peak vulnerability window to the neurotoxicity is during synaptogenesis phase, also called brain growth spurt period $(4,5)$. Such damage may affect the development of the neural network, and the effect may persist to adult age for the behavior and recognition ability $(6,7)$. These findings raised the concerns about the neurotoxicity of general anesthetics, particularly the drugs used in pediatric anesthesia, where the human fetal brain may be damaged during the procedure (8).

Neuron apoptosis is the primary reason for the neurotoxicity, and the mechanisms of anesthesia-induced apoptosis have been well studied $(5,9)$. Activation of proapoptotic proteins such as Bax, may lead to mitochondrial membrane breakage and activation of caspases, which execute cell apoptosis (10). On the other hand, generation of free radicals such as reactive oxygen species (ROS) and reactive nitrogen species (RNS) leads to lipid peroxidation, which could cause brain damage. Such free radicals and damages may also elicit inflammatory responses, which further amplify the apoptotic response (11). By contrast, antioxidant enzymes such as superoxide dismutase (SOD), can scavenge excessive free radicals and alleviate their detrimental effect (12).

Astragaloside IV (AS IV) is a saponin purified from a traditional Chinese herbal medicine component Astragalus membraneaceus (Fisch.) Bunge $(13,14)$. AS IV has exhibited antioxidant activity and anti-apoptosis function in various types of cells and tissues (15-19). For example, it ameliorates renal fibrosis by inhibiting mitogen-activated protein kinase (MAPK) activation and attenuating unilateral ureteralobstruction and transforming grow th factor- $\beta$-induced renal tubular cell apoptosis $(19,20)$. By contrast, AS IV is able to protect neuron cells from 1-methyl-4-phenylpyridnium ion-induced neurotoxicity by preventing ROS production and 
inhibition of the Bax-mediated proapoptotic pathway (21). AS IV also reduced amyloid- $\beta-1-42$-induced neurotoxicity by inhibiting the mitochrondrial permeability transition pore opening (22). However, its role in anesthesia-induced neuroapoptosis and associated neurotoxicity has not been investigated.

To determine whether AS IV is able to protect developing neurons from anesthesia-induced apoptosis, we investigated the effect of AS IV pre-treatment on isoflurane-induced neuron apoptosis in hippocampus tissues of new born rats. The levels of oxidative stress-related enzyme activities in hippocampus tissues and serum were quantified, and serum levels of proinflammatory cytokines were determined by ELISA. Protein expression levels of nuclear factor (NF) $-\mathrm{kB}$, caspase-3, B-cell lymphoma 2 (Bcl-2), phosphorylated (p)-c-Jun N-terminal kinase (JNK), extracellular signal-regulated kinase (ERK) and protein kinase B (Akt) were detected by western blot assay. The results suggested that AS IV had a protective effect in preventing isoflurane-induced neurodegeneration, and indicated a potential mechanism underlying such a protective effect. Overall, the present study provides novel experimental evidence regarding the role of AS IV as a potential means for reducing anesthesia-associated neurotoxicity.

\section{Materials and methods}

Animals and reagents. A total of 20 male Sprague-Dawley rats at five days postpartum (P5) with body weight of 18-25 g were obtained from the animal experiment facility of the Shanghai Institute of Brain Functional Genomics Institute (Eastern China Normal University, Shanghai, China). All animal experiments were approved by the Institutional Animal Care and Use Committee. AS IV was purchased from Sigma-Aldrich (St. Louis, MO, USA), and dissolved in $100 \%$ ethanol, then diluted in $0.9 \%$ saline. Isoflurane was purchased from Abbott Laboratories (Lake Bluff, IL, USA). Terminal deoxynucleotidyl transferase-mediated dUTP nick-end labeling (TUNEL) apoptosis detection kit was from Roche Diagnostics (Rotkreuz, Switzerland). Antibodies against Akt (cat. no. 9272), phospho-Akt (p-Akt; cat. no. 4060), JNK (cat. no. 9252), p-JNK (cat.no.4668),ERK (cat.no.4695), p-ERK (cat.no.4370), NF-кB p65 (cat. no. 8242), histone H3 (cat. no. 4499) and glyceraldehyde 3-phosphate dehydrogenase (GAPDH; cat. no. 5174) were purchased from Cell Signaling Technology, Inc. (Danvers, MA, USA). Antibodies against caspase-3 (cat. no. ab2171), glycogen synthase kinase (GSK)-3 $\beta$ (cat. no. ab32391), p-GSK-3 $\beta$ (cat. no. ab75814) and Klotho (cat. no. ab181373) were purchased from Abcam, Inc. Anti-BCL2 was from Santa Cruz Biotechnology, Inc. (La Jolla, CA, USA). BCA protein quantification kit was from Thermo Fisher Scientific, Inc. (Waltham, MA, USA). RIPA buffer and the IMS cell image analysis software was from Shanghai JRDUN Biotechnology, Co., Ltd., (Shanghai, China).

Experiment groups and anesthesia procedure. The rats (P5) were randomly divided into five groups ( $\mathrm{n}=4 /$ group), as follows: Inhaled isoflurane group; isoflurane + AS IV pre-treatment $(10,40$ or $100 \mathrm{mg} / \mathrm{kg})$ groups; and sham group without anesthesia. The rats were administered AS IV pre-treatment for three days at $0,10,40$ or $100 \mathrm{mg} / \mathrm{kg} / \mathrm{day}$, then exposed to anesthesia. The sham group was pre-treated with ethanol in $0.9 \%$ saline vehicle. The general anesthetics procedure was performed on a platform over a water bath at $37-38^{\circ} \mathrm{C}$. The isoflurane was flowed by oxygen at a concentration of $1.3 \%$. The isoflurane concentration, oxygen concentration and $\mathrm{CO}_{2}$ concentration inside the incubator were regulated using a monitoring machine (Datex-Ohmeda, Inc., Madison, WI, USA). The rats were monitored for $\mathrm{SpO}_{2}$, skin color and breathing frequency. The body orientation was frequently changed to maintain $\mathrm{SpO}_{2}$ at $>90 \%$ during the 3-h anesthesia. Sham group rats were placed in the incubator with air only.

Sample preparation, ELISA and biochemistry analysis. Rats were injected with phenobarbital $(100 \mathrm{mg} / \mathrm{kg})$ and sacrificed by $\mathrm{CO}_{2}$ asphyxiation at $12 \mathrm{~h}$ post-anesthesia, and placed on ice. Then the hippocampus tissues from rat brains were isolated. One part was fixed by $10 \%$ formalin for $12 \mathrm{~h}$ at $4^{\circ} \mathrm{C}$, then transferred into $50 \%$ ethanol for $4-5 \mathrm{~h}$. The tissues were processed for histology slides at $5-\mu \mathrm{m}$ and subjected to hematoxylin and eosin (H\&E) staining. Another part was dissolved in RIPA lysis buffer, and protein was isolated for western blot assay or to undergo biochemical analysis of enzymatic activities. Tumor necrosis factor (TNF)- $\alpha$, interleukin (IL)- 6 and IL-1 $\beta$ levels were measured in blood and brain tissue collected at $12 \mathrm{~h}$ after isofluorane exposure using ELISA kits from R\&D Systems, Inc. (Minneapolis, MN, USA). Blood samples were centrifuged at 3,000 $\mathrm{x}$ for $10 \mathrm{~min}$, and the serum was separated and stored at $-80^{\circ} \mathrm{C}$ until assayed. For detecting TNF- $\alpha$, IL- 6 and IL- $1 \beta$ in brain tissue, frozen tissue samples were weighed and homogenized, then centrifuged at $12,000 \times \mathrm{g}$ for $10 \mathrm{~min}$. The supernatants were stored at $-80^{\circ} \mathrm{C}$ prior to analysis. The nitric oxide (NO) and malondialdehyde (MDA) levels and enzyme activities of nitric oxide synthase (iNOS) and superoxide dismutase (SOD) were quantified using analytical kits from the Nanjing Jiancheng Biological Engineering Institute (Nanjing, China), following manufacturers' instruction.

Western blot analysis. Brain tissues were cut into small pieces and homogenized in RIPA buffer containing protease and phosphatase inhibitors. The samples were centrifuged at $21,952 \mathrm{x} \mathrm{g}$ for $15 \mathrm{~min}$ at $4^{\circ} \mathrm{C}$. The supernatant was quantified for protein concentration using the BCA method and stored at $-80^{\circ} \mathrm{C}$ until use. The nuclear and cytosolic fractions were separated using the nuclear and cytoplasmic extraction buffers for detecting NF- $\mathrm{kB}$ p65 protein. Equal quantities of protein from each sample $(80 \mu \mathrm{g})$ were loaded per lane and separated on $10 \%$ SDS-polyacrylamide gels. The resolved proteins were electrophoretically transferred to nitrocellulose membranes (EMD Millipore, Billerica, MA, USA), then blocked in $5 \%$ nonfat milk for $1 \mathrm{~h}$, followed by overnight primary antibody incubation at $4^{\circ} \mathrm{C}$. The primary antibodies used were anti-NF- $\mathrm{B}$ p65 (1:1,000), anti-H3 (1:800), anti-Akt $(1: 1,000)$, anti-ERK $(1: 1,000)$, anti-JNK $(1: 1,000)$, anti-Bcl-2 (1:100), anti-GSK-3 $\beta$ (1:500), anti-Klotho (1:800) and anti-GAPDH $(1: 1,500)$. Subsequently the membranes were washed three times with Tris-buffered saline with $0.1 \%$ Tween-20, then incubated for $1 \mathrm{~h}$ with horseradish peroxidase-conjugated goat anti-rabbit secondary antibody 
(1:4,000; cat. no. ab6721; Abcam, Inc.) at room temperature. The membranes were then incubated with enhanced chemiluminescence detection reagents and exposed to X-ray films. The optical density of the bands was measured using the ChemiDoc $^{\mathrm{TM}}$ Imaging System (Bio-Rad laboratories Inc., Hercules, CA, USA).

Apoptosis measurement. The TUNEL assay was performed using a commercially available kit (Thermo Fisher Scientific, Inc.), according to the manufacturer's protocol. Six CA1 areas from each slide were selected and analyzed for the positive cell number using the IMS cell image analysis system. TUNEL positive cells are apoptotic cells with dispersed distribution with condensed chromosomes, and manifested with brown particles in nucleus. The number of apoptotic cells in each field was counted for samples from different groups.

Statistic analysis. All the results were presented as the mean \pm standard deviation. SPSS software, version 13.0 (SPSS, Inc., Chicago, IL, USA) was used for analysis. Differences among groups were compared using one-way analysis of variance, followed by Bonferroni post-hoc test. $\mathrm{P}<0.05$ was considered to indicate a statistically significant difference.

\section{Results}

Isoflurane-induced neuron apoptosis in hippocampus CAI region. We observed the tissue damage in hippocampus area in isofluorane-exposed rats, while there were few dead cells in hippocampus CA1 neuron in sham group rats (Fig. 1A and B); however, the number of dead cells showing shrunken cytoplasm and degenerated nuclei increased in tissues from the isoflurane-treated group. These results suggested that isoflurane exposure induced neuron cell death. By contrast, AS IV treatment (Fig. 1C-E) reduced isoflurane-induced neuron cell death. This indicated that AS IV exerts neuroprotective effects on isoflurane-induced neuron cell damage in the CA1 region of hippocampus in rats. To confirm whether the dead cells identified in the H\&E stained tissues were apoptotic cells, we further examined cell apoptosis in these tissues by TUNEL assay (Fig. 2A). In the sham group, the neuron in hippocampus CA1 zone was rarely stained positive in the TUNEL assay. Isoflurane exposure significantly increased the apoptotic neuron numbers $(\mathrm{P}<0.05$ vs. sham group, Fig. 2B). This indicates that the neurodegenerative damage caused by isoflurane was primarily a result of hippocampus neuron apoptosis. By contrast, AS IV treatment (40 and $100 \mathrm{mg} / \mathrm{kg}$ ) significantly reduced isoflurane-induced neuron cell apoptosis $(\mathrm{P}<0.01)$.

SOD, iNOS, MDA and NO measurement in hippocampus tissue and rat serum. To test the levels of isoflurane-induced oxidative stress in different groups, we isolated rat serum and hippocampus tissues and measured the enzyme activities of a number of oxidative stress-associated antioxidant enzymes, including SOD, iNOS, the lipid peroxide marker MDA and NO. In the sham group, MDA levels were relatively low in the hippocampus CA1 zone and rat serum of the sham group
(Figs. 3 and 4). Isoflurane exposure significantly inhibited the enzyme activities of total iNOS, SOD and NO ( $\mathrm{P}<0.01$ vs. sham), but increased MDA levels, which may contribute to the neuron apoptosis. By contrast, AS IV treatment (40 and $100 \mathrm{mg} / \mathrm{kg}$ ) significantly inhibited isoflurane-induced MDA production and ameliorated the suppression of iNOS and SOD enzyme activity and NO production by isoflurane (Figs. 3 and 4).

Proinflammatory cytokine measurement in the serum and culture supernatant. To test the levels of isoflurane-induced proinflammatory responses in different groups, we isolated rat serum and measured levels of the major proinflammatory cytokines TNF- $\alpha$, IL-6 and IL-1 $\beta$ (Fig. 5). In the sham group, these cytokine levels were relatively low in rat serum. Isoflurane exposure significantly increased the levels of all the three proinflammatory cytokines $(\mathrm{P}<0.01)$. By contrast, AS IV treatment (10, 40 and $100 \mathrm{mg} / \mathrm{kg}$ groups) significantly reduced isoflurane-induced proinflammatory cytokine release $(\mathrm{P}<0.01)$. These results suggested that isoflurane exposure induced systemic inflammatory responses in neonatal rats, and AS IV alleviated such inflammation.

Inflammatory and antiapoptotic signaling pathway analysis. The proinflammatory cytokine responses and reactive nitrogen species production are primarily regulated by the $\mathrm{NF}-\kappa \mathrm{B}$ pathway. Thus, we measured the $\mathrm{NF}-\kappa \mathrm{B}$ activity in rat hippocampus tissues by western blot. In protein samples from the sham group, NF- $\mathrm{KB}$ protein was detected predominantly in the cytoplasm and levels were low in the nucleus, suggesting low NF- $\mathrm{B}$ activity (Fig. 6A). Isoflurane exposure markedly increased nuclear levels of $\mathrm{NF}-\kappa \mathrm{B}$ protein, indicating $\mathrm{NF}-\kappa \mathrm{B}$ activation in hippocampus tissue. By contrast, AS IV treatment reduced isoflurane-induced $\mathrm{NF}-\kappa \mathrm{B}$ nuclear localization, indicating suppressed $\mathrm{NF}-\kappa \mathrm{B}$ activation (Fig. 6A).

We further measured the expression levels of a number of apoptosis-associated proteins in different groups. In protein samples from the sham group, the expression of the proapoptotic marker protein caspase-3 was relatively low. By contrast, the antiapoptotic marker protein Bcl-2 was abundantly expressed. Isoflurane exposure markedly increased caspase-3 protein levels and decreased Bcl-2 protein levels (Fig. 6B). By contrast, AS IV treatment inhibited isoflurane-induced caspase-3 upregulation and Bcl-2 downregulation, suggesting that AS IV suppressed isoflurane-induced hippocampus apoptosis. Similarly, isoflurane exposure induced GSK-3 $\beta$ and decreased Klotho and phosphorylated Akt protein levels; however, AS IV pre-treatment inhibited isoflurane-induced changes in these proteins.

MAPK signaling pathways are intricately involved in apoptotic responses (23). We observed the activation of JNK and ERK by isoflurane exposure; indicated by increased phosphorylated protein levels. Furthermore, AS IV treatment inhibited isoflurane-induced MAPK activation (Fig. 6B).

\section{Discussion}

Apoptotic neuron cell death after anesthesia exposure has an important consequence in neurotoxicity (24). The two 
A

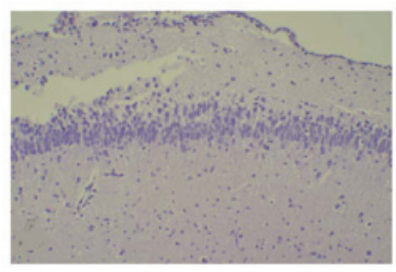

B

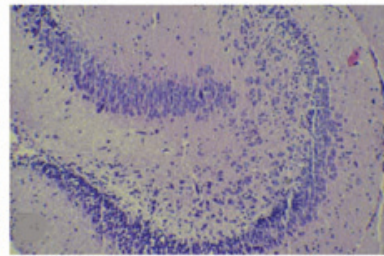

C

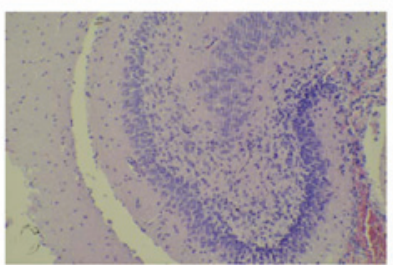

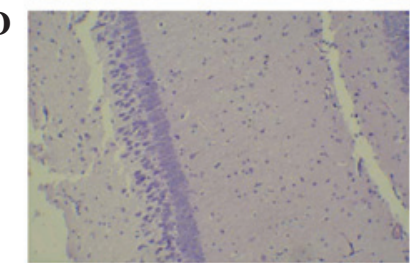

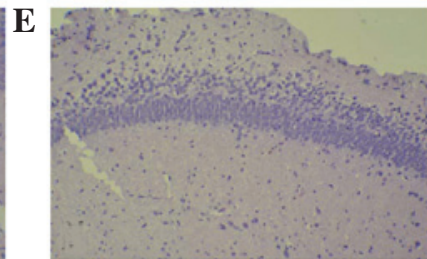

Figure 1. Hematoxylin and eosin staining on hippocampus CA1 region tissues of newborn rats after isoflurane exposure with or without AS IV pre-treatment (magnification, x10). (A) Sham, (B) isoflurane, (C) isoflurane + AS IV (10 mg/kg), (D) isoflurane + AS IV (40 mg/kg) and (E) isoflurane + AS IV (100 mg/kg) Note that a marked neuronal loss occurred in (B) compared with (A), whereas AS IV pre-treated groups (C-E) showed reduced neuron death compared with (B). AS IV, astragaloside IV.

$\mathbf{A}$

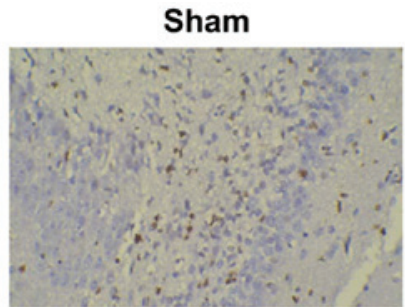

Isofluorane

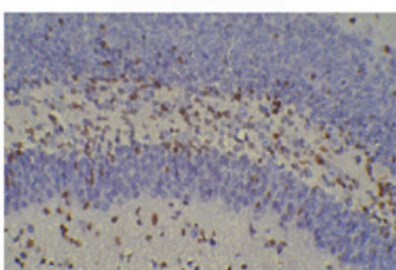

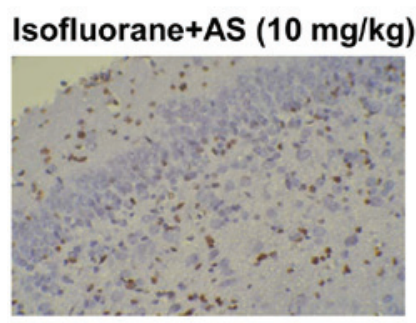
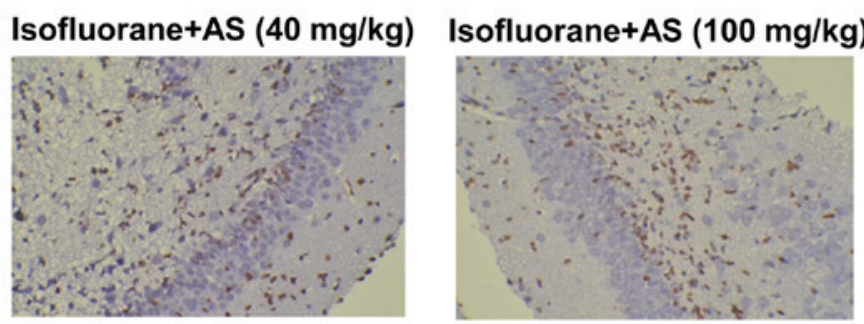

B
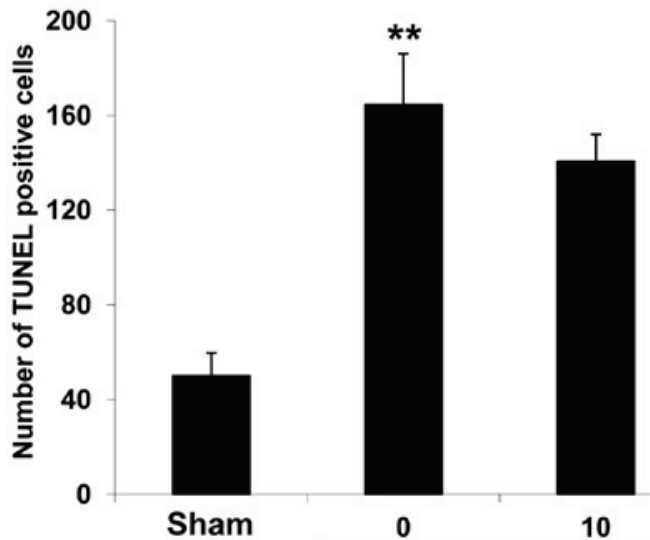

10

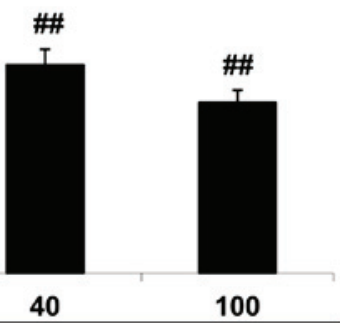

Isofluorane + AS IV (mg/kg)

Figure 2. Effect of AS IV on isoflurane-induced hippocampus neuron cell apoptosis. (A) Representative TUNEL staining of rat hippocampus tissues from different groups (magnification, $\mathrm{x} 40$ ). (B) Numbers of TUNEL positive cells per area from hippocampus tissues of different groups. ${ }^{* *} \mathrm{P}<0.01$ vs. sham group; ${ }^{\# \#} \mathrm{P}<0.01$ vs. AS IV $(0 \mathrm{mg} / \mathrm{kg})$. AS IV, astrogaloside IV.

major pathways for cell apoptosis are the death receptor (Fas and TNFR)-mediated intrinsic pathway and mitochondria pathway (24). The mitochondria pathway can be activated by extrinsic and intrinsic stimuli, which includes oxidation and cytotoxic drug treatment. For the immature animal brain, particularly in specific development stages such as synaptogenesis period, general anesthesia can induce severe neurotoxicity, and mitochondria pathway 

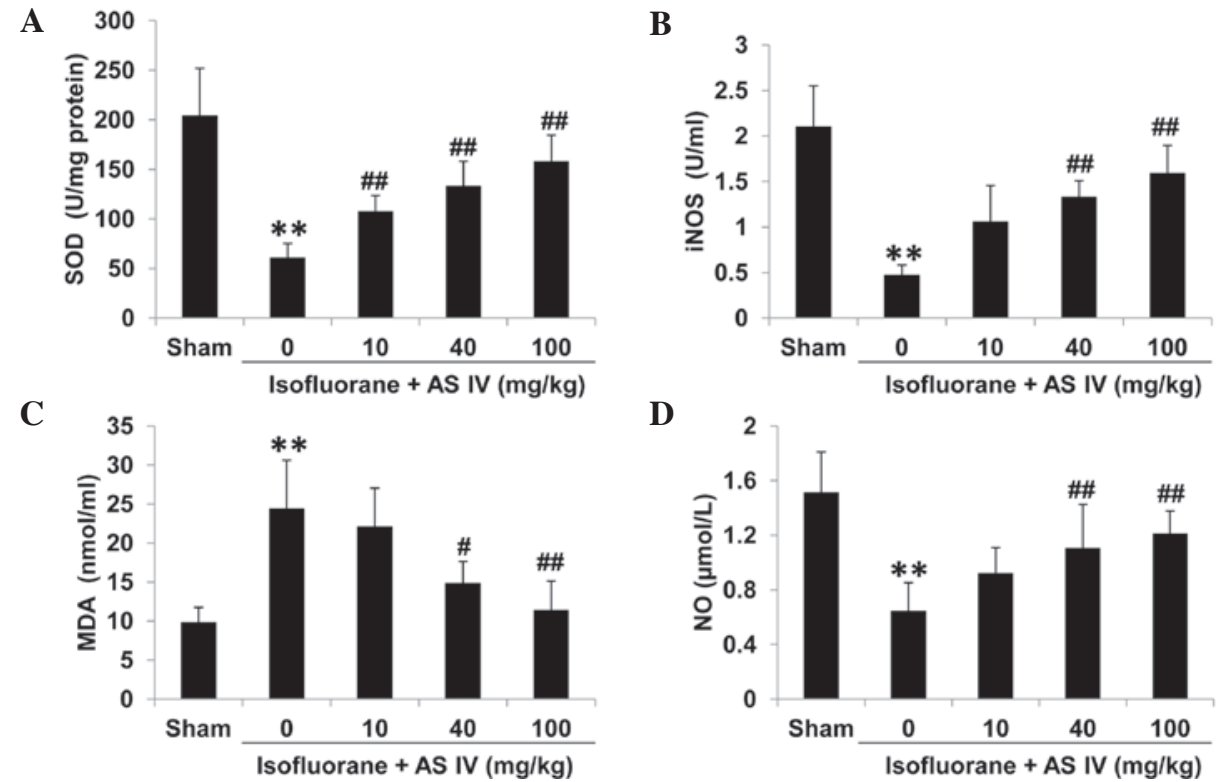

Figure 3. AS IV inhibited isoflurane-induced nitrogen species production in hippocampus tissues. (A) SOD and (B) iNOS activity, (C) MDA and (D) NO levels detected in rat hippocampus tissues at $12 \mathrm{~h}$ post-anesthesia. ${ }^{* *} \mathrm{P}<0.01 \mathrm{vs}$. Sham group; ${ }^{*} \mathrm{P}<0.05,{ }^{* \#} \mathrm{P}<0.01 \mathrm{vs}$. AS IV $(0 \mathrm{mg} / \mathrm{kg})$. AS IV, astragaloside IV; SOD, superoxide dismutase; iNOS, nitric oxide synthase; MDA, malondialdehyde; NO, nitric oxide.
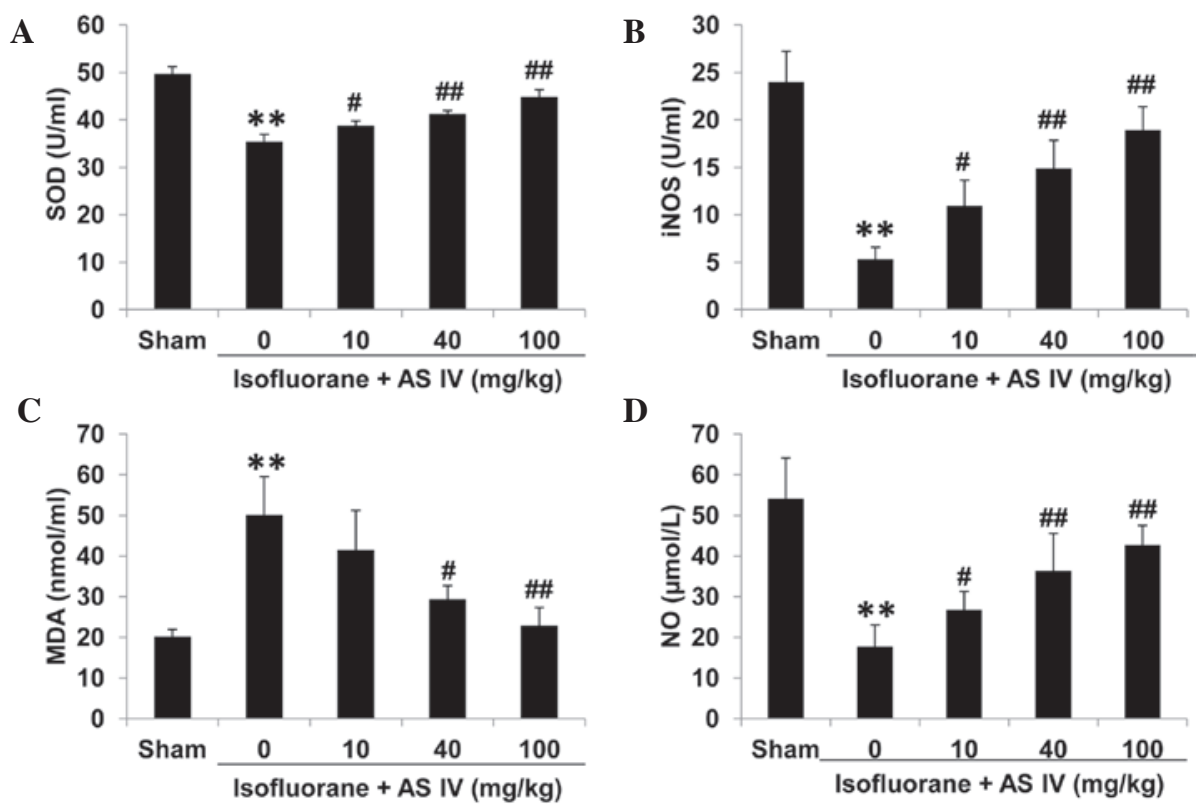

Figure 4. AS IV inhibited isoflurane-induced nitrogen species production in rat serum. (A) SOD and (B) iNOS activity, (C) MDA and (D) NO levels detected in rat sera at $12 \mathrm{~h}$ post-anesthesia. ${ }^{* *} \mathrm{P}<0.01$ vs. Sham group; $\mathrm{P}<0.05,{ }^{\# \#} \mathrm{P}<0.01 \mathrm{vs}$. AS IV (0 mg/kg). AS IV, astragaloside IV; SOD, superoxide dismutase; iNOS, nitric oxide synthase; MDA, malondialdehdye; NO, nitric oxide.
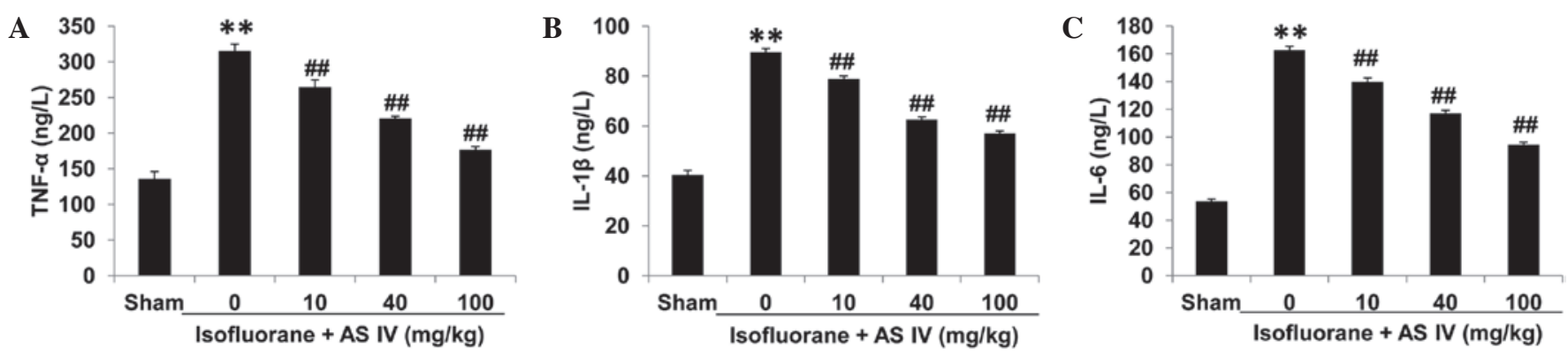

Figure 5. AS IV reduced isoflurane-induced proinflammatory cytokine production in rat serum. (A) TNF- $\alpha$, (B) IL-1 $\beta$ and (C) IL-6 levels detected in rat sera at $12 \mathrm{~h}$ post-anesthesia. ${ }^{* *} \mathrm{P}<0.01$ vs. Sham group; ${ }^{\# \#} \mathrm{P}<0.01$ vs. AS IV $(0 \mathrm{mg} / \mathrm{kg})$. TNF- $\alpha$, tumor necrosis factor- $\alpha$; AS IV, astragaloside IV; IL, interleukin. 
A
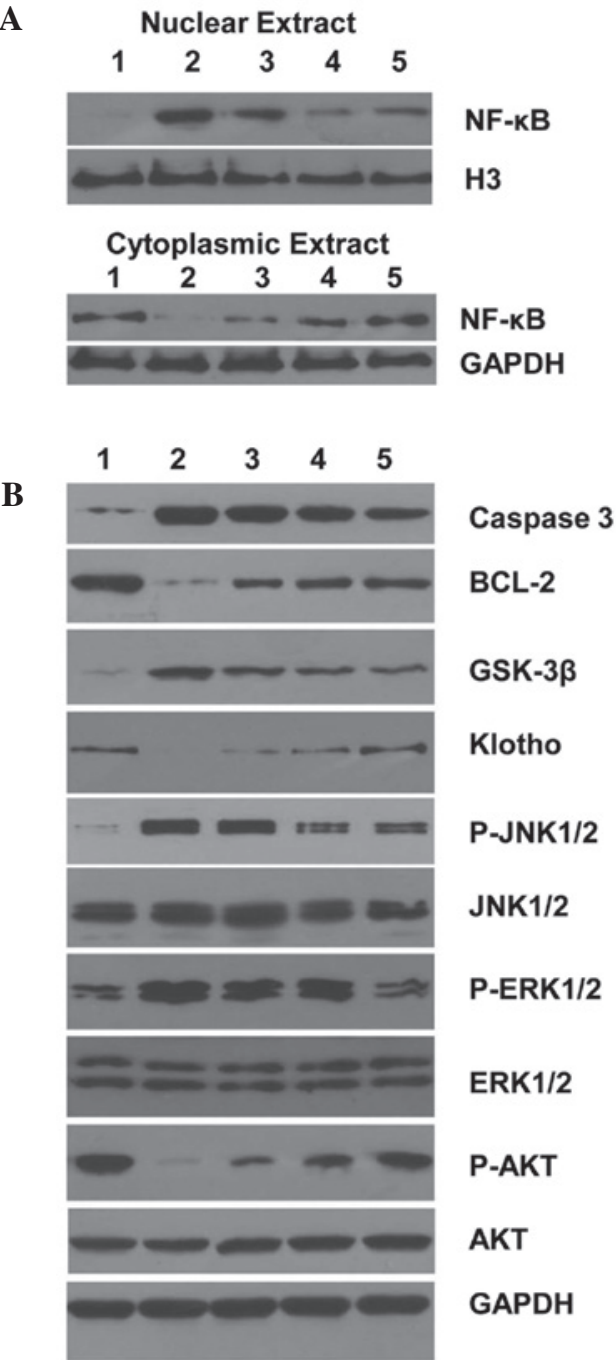

Figure 6. Astragaloside IV (AS IV) attenuated isoflurane-induced NF-кB activation and apoptotic pathway activation in hippocampus tissues. Lane 1: Sham group; 2: Isoflurane group; 3: Isoflurane + AS IV (10 mg/kg); 4: Isoflurane + AS IV $(40 \mathrm{mg} / \mathrm{kg})$; and 5: Isoflurane + AS IV $(100 \mathrm{mg} / \mathrm{kg})$. (A) Cytoplasmic and nuclear NF-kB levels from rat hippocampus tissues. Histone $\mathrm{H} 3$ and GAPDH were used as loading control for nuclear protein and cytoplasmic protein, respectively. (B) Expression levels of apoptosis-related proteins in total cell lysates from rat hippocampus tissues were determined by western blot assay. GAPDH levels were used for equal loading control

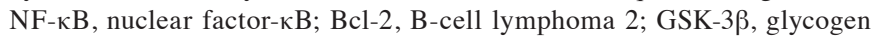
synthase kinase $3 \beta$; JNK, c-Jun N-terminal kinase; ERK, extracellular signal-regulated kinase; AKT, protein kinase B; GAPDH, glyceraldehyde 3-phosphate dehydrogenase.

activation is considered the initial step (5). The key step is cytochrome $\mathrm{c}$ release from mitochondria to the cytoplasm, and the mechanism is that isoflurane may activate IP3 receptor on endoplasmic reticulum and disrupt the calcium homeostasis, and changed the structure and function of the outer membrane-located Bcl-2 family proteins, mitochrondrial permeability transition, MPT and the channel (MPT pore) (25). Clinically, a mixture of laughing gas and isoflurane has been shown to activate the mitochondria pathway in neurons by downregulating antiapoptotic protein $\mathrm{Bcl}-\mathrm{xL}$, and immature brains are even more sensitive to isoflurane-induced neuron apoptosis by increasing proapoptotic protein Bax, decreasing antiapoptotic protein $\mathrm{Bcl}-2$, and allowing free radical accumulation and cytochrome $\mathrm{c}$ release into cytoplasm, initiating apoptosis (26). A similar neurodegenerative effect was observed in the present study.

Oxidative stress, which is a result of the overproduction and accumulation of free radicals, including ROS and RNS, plays a major role in a variety of neurological pathogenesis (27). Disruption of the balance of free radical generation and antioxidant enzyme system may result in oxidative stress. Previous studies have reported that AS IV is an effective free radical scavenger and potentiates the intrinsic antioxidant system in the animal model of cerebral ischemia/reperfusion (16). In the present study, the results indicated that AS IV enhanced intrinsic antioxidant enzyme activity and decreased RNS accumulation in the hippocampus tissue and serum.

Notably, we also observed a systemic increase of proinflammatory cytokines (TNF- $\alpha$, IL-1 $\beta$ and IL-6) in neonatal rats following isoflurane exposure, suggesting an inflammatory responses triggered by the anesthesia procedure. AS IV also exhibited anti-inflammatory activity, in this case by alleviating anesthesia-induced proinflammatory cytokine production. As a master regulator of inflammatory responses and cell survival, NF- $\mathrm{KB}$ activation has been documented in multiple neurological pathology conditions (28). Although $\mathrm{NF}-\mathrm{\kappa B}$ is primarily a survival factor in numerous cell types, its role in neuronal apoptosis may vary depending on the specific contexts and treatments (29). In the present study, we observed isoflurane-induced NF- $\mathrm{KB}$ activation, which could be from accumulated oxidative stress. Crucially, AS IV reduced such NF- $\mathrm{NB}$ activation, and ameliorated systemic proinflammatory cytokine production.

It has been reported that isoflurane exposure downregulates Bcl-2 and ERK signaling in the developing rat brain (30). However, we identified increased level of phosphorylated ERK and JNK in neuron cells after isoflurane exposure. The JNK pathway is generally considered a proapoptotic pathway, while ERK signaling is often considered neuroprotective (23). However, MAPKs are often activated simultaneously in response to stress or stimulation (23). Thus, we consider ERK activation as an early reaction in response to isoflurane exposure; however, its neuroprotective effect may be masked by other signaling pathways such as JNK pathway.

AS IV is a potent agent for antioxidant and ROS clearance. AS IV may inhibit oxidized product formation in cell membrane and nuclear DNA adducts, reduce the accumulation of ROS inside the mitochondria and alleviate oxidative stress-induced cell apoptosis $(17,21)$. AS IV has been speculated to exert a protective effect in treating degenerative diseases in central neural system, such as Alzheimer's disease, Parkinson's disease, ischemia-reperfusion-induced brain damage, and physical damage in the brain $(15,22,31,32)$. The results of the present study confirmed that AS IV is protective against isoflurane-induced neuronal degeneration in the developing rat brain. The underlying mechanism may be associated with the inhibition of oxidative stress and inflammation in the hippocampus region and systemic level, thereby reducing abnormal apoptosis of developing neuron. Thus, the antiapoptotic and antioxidative function of AS IV in general anesthesia-induced neuron toxicity may have potential clinical relevance. 


\section{References}

1. Ikonomidou C, Bosch F, Miksa M, Bittigau P, Vöckler J, Dikranian K, Tenkova TI, Stefovska V, Turski L and Olney JW: Blockade of NMDA receptors and apoptotic neurodegeneration in the developing brain. Science 283: 70-74, 1999.

2. Ikonomidou C, Bittigau P, Ishimaru MJ, Wozniak DF, Koch C, Genz K, Price MT, Stefovska V, Hörster F, Tenkova T, et al: Ethanol-induced apoptotic neurodegeneration and fetal alcohol syndrome. Science 287: 1056-1060, 2000.

3. Jevtovic-Todorovic V, Hartman RE, Izumi Y, Benshoff ND, Dikranian K, Zorumski CF, Olney JW and Wozniak DF: Early exposure to common anesthetic agents causes widespread neurodegeneration in the developing rat brain and persistent learning deficits. J Neurosci 23: 876-882, 2003.

4. Dobbing J and Sands J: Comparative aspects of the brain growth spurt. Early Hum Dev 3: 79-83, 1979.

5. Felderhoff-Mueser U and Ikonomidou C: Mechanisms of neurodegeneration after paediatric brain injury. Curr Opin Neurol 13 $141-145,2000$

6. Fredriksson A, Pontén E, Gordh T and Eriksson P: Neonatal exposure to a combination of $\mathrm{N}$-methyl-D-aspartate and gamma-aminobutyric acid type A receptor anesthetic agents potentiates apoptotic neurodegeneration and persistent behavioral deficits. Anesthesiology 107: 427-436, 2007.

7. Wilder RT, Flick RP, Sprung J, Katusic SK, Barbaresi WJ, Mickelson C, Gleich SJ, Schroeder DR, Weaver AL and Warner DO: Early exposure to anesthesia and learning disabilities in a population-based birth cohort. Anesthesiology 110 796-804, 2009.

8. Servick K: Biomedical Research. Researchers struggle to gauge risks of childhood anesthesia. Science 346: 1161-1162, 2014.

9. Olney JW, Ishimaru MJ, Bittigau P and Ikonomidou C: Ethanol-induced apoptotic neurodegeneration in the developing brain. Apoptosis 5: 515-521, 2000.

10. Renault TT, Floros KV, Elkholi R, Corrigan KA, Kushnareva Y, Wieder SY, Lindtner C, Serasinghe MN, Asciolla JJ Buettner C, et al: Mitochondrial shape governs BAX-induced membrane permeabilization and apoptosis. Mol Cell 57: 69-82, 2015.

11. Yin $\mathrm{H}$ and $\mathrm{Zhu} \mathrm{M}$ : Free radical oxidation of cardiolipin: Chemical mechanisms, detection and implication in apoptosis, mitochondrial dysfunction and human diseases. Free Radic Res 46: 959-974, 2012.

12. Jawaid P, ur Rehman M, Yoshihisa Y, Li P, Zhao Ql, Hassan MA, Miyamoto Y, Shimizu T and Kondo T: Effects of SOD/catalase mimetic platinum nanoparticles on radiation-induced apoptosis in human lymphoma U937 cells. Apoptosis 19: 1006-1016, 2014

13. Li M, Wang W, Xue J, Gu Y and Lin S: Meta-analysis of the clinical value of Astragalus membranaceus in diabetic nephropathy. J Ethnopharmacol 133: 412-419, 2011.

14. Matkovic Z, Zivkovic V, Korica M, Plavec D, Pecanic S and Tudoric N: Efficacy and safety of Astragalus membranaceus in the treatment of patients with seasonal allergic rhinitis. Phytother Res 24: 175-181, 2010.

15. Qu YZ, Li M, Zhao YL, Zhao ZW, Wei XY, Liu JP, Gao L and Gao GD: Astragaloside IV attenuates cerebral ischemia-reperfusion-induced increase in permeability of the blood-brain barrier in rats. Eur J Pharmacol 606: 137-141, 2009

16. Li M, Ma RN, Li LH, Qu YZ and Gao GD: Astragaloside IV reduces cerebral edema post-ischemia/reperfusion correlating the suppression of MMP-9 and AQP4. Eur J Pharmacol 715: $189-195,2013$
17. He Y, Du M, Gao Y, Liu H, Wang H, Wu X and Wang Z: Astragaloside IV attenuates experimental autoimmune encephalomyelitis of mice by counteracting oxidative stress at multiple levels. PLoS One 8: e76495, 2013.

18. Gui D, Huang J, Guo Y, Chen J, Chen Y, Xiao W, Liu X and Wang N: Astragaloside IV ameliorates renal injury in streptozotocin-induced diabetic rats through inhibiting $\mathrm{NF}-\kappa \mathrm{B}-\mathrm{mediated}$ inflammatory genes expression. Cytokine 61: 970-977, 2013

19. Ding Y, Yuan S, Liu X, Mao P, Zhao C, Huang Q, Zhang R, Fang Y, Song Q, Yuan D, et al: Protective effects of astragaloside IV on db/db mice with diabetic retinopathy. PLoS One 9: e112207, 2014

20. Xu W, Shao X, Tian L, Gu L, Zhang M, Wang Q, Wu B, Wang L, Yao J, Xu X, et al: Astragaloside IV ameliorates renal fibrosis via the inhibition of mitogen-activated protein kinases and antiapoptosis in vivo and in vitro. J Pharmacol Exp Ther 350: 552-562, 2014

21. Zhang ZG, Wu L, Wang JL, Yang JD, Zhang J, Zhang J, Li LH, Xia Y, Yao LB, Qin HZ and Gao GD: Astragaloside IV prevents $\mathrm{MPP}^{+}$-induced SH-SY5Y cell death via the inhibition of Bax-mediated pathways and ROS production. Mol Cell Biochem 364: 209-216, 2012

22. Sun Q, Jia N, Wang W, Jin H, Xu J and Hu H: Protective effects of astragaloside IV against amyloid beta1-42 neurotoxicity by inhibiting the mitochondrial permeability transition pore opening. PLoS One 9: e98866, 2014.

23. Miloso M, Scuteri A, Foudah D and Tredici G: MAPKs as mediators of cell fate determination: An approach to neurodegenerative diseases. Curr Med Chem 15: 538-548, 2008.

24. Friedlander RM: Apoptosis and caspases in neurodegenerative diseases. N Engl J Med 348: 1365-1375, 2003.

25. Yang H, Liang G, Hawkins BJ, Madesh M, Pierwola A and Wei H: Inhalational anesthetics induce cell damage by disruption of intracellular calcium homeostasis with different potencies. Anesthesiology 109: 243-250, 2008.

26. Blaylock M, Engelhardt T and Bissonnette B: Fundamentals of neuronal apoptosis relevant to pediatric anesthesia. Paediatr Anaesth 20: 383-395, 2010

27. Skowrońska M and Albrecht J: Oxidative and nitrosative stress in ammonia neurotoxicity. Neurochem Int 62: 731-737, 2013.

28. Karin $\mathrm{M}$ and Lin A: NF-kappaB at the crossroads of life and death. Nat Immunol 3: 221-227, 2002.

29. Mincheva-Tasheva $S$ and Soler RM: NF- $\kappa B$ signaling pathways: Role in nervous system physiology and pathology. Neuroscientist 19: 175-194, 2013.

30. Sanders RD, Sun P, Patel S, Li M, Maze M and Ma D: Dexmedetomidine provides cortical neuroprotection: Impact on anaesthetic-induced neuroapoptosis in the rat developing brain. Acta Anaesthesiol Scand 54: 710-716, 2010.

31. Shao A, Guo S, Tu S, Ammar AB, Tang J, Hong Y, Wu H and Zhang J: Astragaloside IV alleviates early brain injury following experimental subarachnoid hemorrhage in rats. Int J Med Sci 11: 1073-1081, 2014.

32. Luo Y, Qin Z, Hong Z, Zhang X, Ding D, Fu JH, Zhang WD and Chen J: Astragaloside IV protects against ischemic brain injury in a murine model of transient focal ischemia. Neurosci Lett 363: 218-223, 2004. 